\title{
Determinants of negative preference for female fetuses amongst women of reproductive age group at rural medical college
}

\author{
Deepti Shrivastava*, Vijaya S. Patil, Sandeep Shrivastava, Juhee Papalkar
}

Department of Obstetrics \& Gynaecology, JNMC, DMIMSU, Sawangi (M), Wardha, Maharashtra, India

Received: 11 January 2013

Accepted: 19 January 2013

*Correspondence:

Dr. Deepti Shrivastava

E-mail: deepti_shrivastava69@yahoo.com

\begin{abstract}
Background: India is experiencing lowest child sex ratio of the world. The deficit of girl children has been progressively increasing, in spite of so many laws to favour them like Sharda act, act against dowry and law against female feticide, i.e. PC \& PNDT. The present study attempted to explore the determinants of negative preference of female fetuses at rural setup and preferences for prevention of female foeticide.

Methods: In a prospective, multicentric, cohort study, 2203 married women of reproductive age group were interviewed by pretested piloted structured questionnaire. SPSS software was used for statistical analysis.

Results: Common causes for not preferring daughters were related to their marriages expenses, dowry along with exogamy and practices regarding death ceremonies of parents. Self deprived image of today's woman by herself is mainly responsible for not allowing her to welcome another girl child in a family.

Conclusions: Female foeticide is still in practice inspite of awareness programmes and existing law. Main reason for it is societal need due to marriage related customs and cultures along with unethical practices by service providers. To increase in self-esteem of women can only reduce the volume of service receiver along with upliftment of moral and ethical values of service providers from the beginning of their medical training can prevent it to happen.
\end{abstract}

Keywords: Negative preferences, Female foeticide, Societal need, Service provider

\section{INTRODUCTION}

Women in India have made a lot of progress in every field of life as a result of technological developments as well as a process of evolution. Though in small numbers, today Indian women are in almost all spheres of life. They are doctors, engineers, pilots, journalists, teachers, administrators, members of parliament and ministers. India has had a woman President and Prime Minister. In spite of these achievements the fact remains that ordinary women's condition is a grim reality, they are still the victims of oppression or of socially prevalent sex biases.

India has today, lowest sex ratio in the world, from centuries, preference of son in India has been expressed in terms of female infanticide that has now being replaced by female foeticide or sex selective abortion, which is thus the conjunction of two ethical evils: abortion and gender bias - A fetus's right to life and that too a female foetus.
The child sex ratio (0-6 years) is a sensitive indicator of status of girl child, it has been declining faster than overall sex ratio. It recorded highest fall during last two decades. Child Sex Ratio (CSR) (914) is lower than Overall Sex Ratio (OSR) (940), which reveals the severity of problem (Table 1 ). ${ }^{1}$

The biological norm for birth ratios is about 105 boys born for every 100 girls worldwide. This norm has been drastically altered in some countries such as China, South Korea and India where the sex-ratio has been skewed since the mid-1980s. With an average of respectively 117 and 120 boys are born for every 100 girls. ${ }^{2}$ Whatever the natural biological laws of human reproduction had given mankind for balancing its natural sex ratio, has been taken away by manmade laws, customs, traditions, religious beliefs and sophisticated medical technology, resulting in a lower status in society for girls. 
Table 1: Child Sex Ratio (CSR) and Overall Sex Ratio (OSR).

\begin{tabular}{|llllllll|}
\hline Year & 1951 & 1961 & 1971 & 1981 & 1991 & 2001 & 2011 \\
\hline CSR & 983 & $976(-7)$ & $964(-12)$ & $962(-2)$ & $945(-17)$ & $927(-18)$ & $914(-13)$ \\
\hline OSR & 946 & $946(-5)$ & $930(-11)$ & $934(+4)$ & $927(-7)$ & $933(+6)$ & $940(+7)$ \\
\hline
\end{tabular}

Source: Census of India, 1961, 1981, $2001 \& 2011^{1}$

The main determinant identified for declining sex ratio is female foeticide. Exploring in depth, female foeticide is a complex phenomenon involving interactions between societal needs, technology, and regulation. ${ }^{3}$ The low and declining sex ratio is an indicator of low status of females in the society and a reflection of gender bias. It is a disgrace for the Indian society, which considers the birth of a girl child as a bad investment in future. She is considered to be consumer rather than a producer, this is on the contrary to the fact that women are worshipped and revered in every form in India. Gender inequality, dowry burden, domestic violence, (as India is the fourth most dangerous place in the world for women to live in) ${ }^{4}$ biologic burden of menstruation, pregnancy and child birth and care needed for their upbringing make the girl very vulnerable.

The present study attempted to explore the determinants of negative preference of female fetuses at rural setup and their views and preferences for prevention of female foeticide.

\section{Aims and Objectives:}

1. To find out determinant factors of negative preference for female foetuses amongst women of reproductive age group of Wardha and similar suburban areas.

2. To formulate preventive measures for further reduction of it.

\section{METHODS}

In a prospective, cohort, hospital-based, descriptive study of 36 months from 1st August 2009 to 1st July 2012; 1500 married women of reproductive age group, who attended the antenatal clinic or admitted at AVBR Hospital attached to Jawaharlal Nehru Medical College, Sawangi, Meghe, Wardha, Maharashtra and 703 women from similar suburban and rural areas of Madhya Pradesh were selected.

A pre-tested and pre-structured questionnaire was used to collect information on their awareness, perception, attitudes and practices toward gender preference and female foeticide by trained interviewers. Both verbal and written informed consent was taken from women to participate in the study. Cross checking of at least two completed forms daily was done randomly by the investigators on a regular basis to ensure good quality data collection. Confidentiality of the data and privacy of the patients was maintained.

The data was coded and entered into Microsoft Excel and analyzed using SPSS software. The Chi-square test for proportions was used as the test of significance. Twotailed $p$ value of less than 0.05 was considered significant.

\section{RESULTS}

\section{Demographic profile of population studied}

In present study approximately $67 \%$ women were of $16-$ 25 years of age group. Majority i.e. approximately $78 \%$ were of rural background, $30 \%$ were educated upto primary level, homemakers were $45 \%$, pregnant $68 \%$, primigravida $44 \%$ and belonged to nuclear family were $55.5 \%$ (Table 2). They were divided in two groups: Group A represented Maharashtra and Group B to Madhya Pradesh for better analysis. Respondents from both the states were almost of similar range without any significant difference. Although absolute percentage of illiterate women $8.1 \%$ vs $6.3 \%$ was, more in MP group and percentage of health workers $18 \%$ Vs $3.8 \%$ was more in MS group but these were not significantly different statistically (Table 2).

Similarly absolute percentage of women with 2 or more children in the family $27 \%$ vs $10 \%$ was also more in MP group. Number of pregnant women with 2 or more females $6.1 \%$ vs $2.9 \%$ was also more in MP group. Number of joint family $51.9 \%$ vs $41 \%$ was also more in MP group; all these were not different statistically.

Presence of One Female In The Family Make Very Strong Son Preference For The Next Child. In the MP Group, It was $100 \%$ after one female (Table 3) at the same time presence of one male made preference for female too. Balancing the family was important for preferring even female foetus especially if first child is male (Table 3).

Most of the women appeared to have self-image or recognition of lowered status of themselves as a woman, and few of them were not even aware about this perception, hence when asked in the leading questions, a large proportion of them were not satisfied regarding their status in the family and had some sort of feeling of deprivement as a woman. This was seen more in MP group. More number of women in MP group needed 
dowry and felt lack of independence while other kind of discriminations as a female were more experienced by
MS group women (Table 4).

Table 2: Socio-demographic profile of population studied.

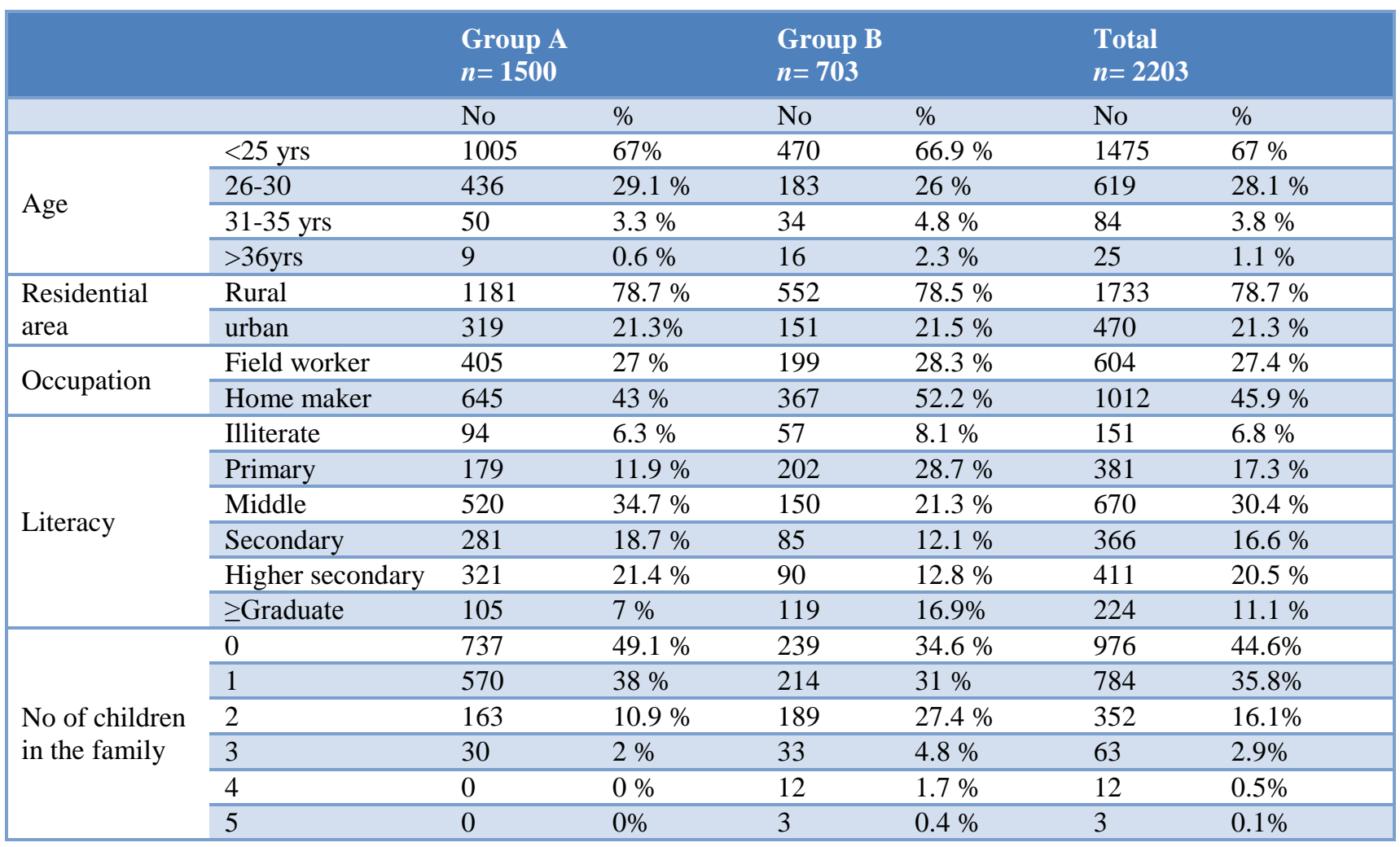

Table 3: Son preference in association with gender of previous child in the family.

\begin{tabular}{|c|c|c|c|c|c|c|c|}
\hline \multirow{2}{*}{ Gender of children } & \multicolumn{2}{|c|}{$\begin{array}{l}\text { Group A } \\
n=1500\end{array}$} & \multirow{2}{*}{ Total } & \multicolumn{2}{|c|}{$\begin{array}{l}\text { Group B } \\
n=703\end{array}$} & \multirow{2}{*}{ Total } & \multirow{2}{*}{$\begin{array}{l}\text { Chi } \\
\text { square/ } \\
\text { df/ } \\
p \text { value }\end{array}$} \\
\hline & $\mathrm{F}$ & M & & $\mathrm{F}$ & $\mathrm{M}$ & & \\
\hline \multirow{2}{*}{1 female } & 44 & 286 & 330 & 0 & 182 & 182 & \multirow{12}{*}{233.932} \\
\hline & $13.3 \%$ & $86.7 \%$ & $100 \%$ & $0 \%$ & $100 \%$ & $100 \%$ & \\
\hline \multirow{2}{*}{1 male } & 59 & 213 & 272 & 48 & 90 & 138 & \\
\hline & $21.7 \%$ & $78.3 \%$ & $100 \%$ & $34.78 \%$ & $65.22 \%$ & $100 \%$ & \\
\hline \multirow{2}{*}{2 females } & 2 & 85 & 87 & 0 & 53 & 53 & \\
\hline & $2.3 \%$ & $97.7 \%$ & $100 \%$ & $0 \%$ & $100 \%$ & $100 \%$ & \\
\hline \multirow{2}{*}{1 male, 1 female } & 15 & 32 & 47 & 13 & 40 & 53 & \\
\hline & $31.9 \%$ & $68.1 \%$ & $100 \%$ & $24.53 \%$ & $75.47 \%$ & $100 \%$ & \\
\hline \multirow{2}{*}{$>2$ females } & 1 & 43 & 44 & 0 & 43 & 43 & \\
\hline & $2.3 \%$ & $97.7 \%$ & $100 \%$ & $0 \%$ & $100 \%$ & $100 \%$ & \\
\hline \multirow{2}{*}{ No issue } & 59 & 661 & 720 & 39 & 195 & 234 & \\
\hline & $8.2 \%$ & $91.8 \%$ & $100 \%$ & $16.67 \%$ & $83.33 \%$ & $100 \%$ & \\
\hline
\end{tabular}


Table 4: Showing their own experience as women (between states).

\begin{tabular}{|c|c|c|c|c|c|c|}
\hline \multirow{2}{*}{ Parameter } & & \multicolumn{2}{|c|}{ Group A } & \multicolumn{2}{|c|}{ Group B } & \multirow{2}{*}{$\begin{array}{l}\text { Chi square/ df/ } \\
p \text { value }\end{array}$} \\
\hline & & No & $\%$ & No & $\%$ & \\
\hline \multirow{2}{*}{$\begin{array}{l}\text { Position in the family } \\
\text { (in terms of feeling of } \\
\text { deprivement) }\end{array}$} & Unsatisfied & 1215 & $81 \%$ & 625 & $88.9 \%$ & \multirow{2}{*}{$\begin{array}{l}21.162 \\
(1) \\
0.001\end{array}$} \\
\hline & Satisfied & 285 & $19 \%$ & 78 & $11.1 \%$ & \\
\hline \multirow{2}{*}{$\begin{array}{l}\text { Needed dowry } \\
\text { /marriage expenses }\end{array}$} & Yes & 1020 & $68 \%$ & 532 & $75.7 \%$ & \multirow{2}{*}{$\begin{array}{l}13.180 \\
(1) \\
0.001\end{array}$} \\
\hline & No & 480 & $32 \%$ & 171 & $24.3 \% \%$ & \\
\hline \multirow[b]{2}{*}{ Other discrimination } & Yes & 1395 & $93 \%$ & 624 & $88.8 \%$ & \multirow{2}{*}{$\begin{array}{l}10.682 \\
(1) \\
0.001 \\
\end{array}$} \\
\hline & No & 105 & $7 \%$ & 79 & $11.2 \%$ & \\
\hline \multirow[b]{2}{*}{ Independence } & Yes & 399 & $26.6 \%$ & 101 & $14.4 \%$ & \multirow{2}{*}{$\begin{array}{l}40.132 \\
(1) \\
0.001\end{array}$} \\
\hline & No & 1101 & $73.4 \%$ & 602 & $85.6 \%$ & \\
\hline
\end{tabular}

Table 5: Women's attitude towards girl child in the family (between states).

\begin{tabular}{|c|c|c|c|c|c|}
\hline \multirow{2}{*}{ Parameter } & & \multicolumn{2}{|c|}{ Group A } & \multicolumn{2}{|c|}{ Group B } \\
\hline & & No & $\%$ & No & $\%$ \\
\hline \multirow{2}{*}{ Diet /food } & Boys preferred & 315 & $21 \%$ & 233 & $33.1 \%$ \\
\hline & No difference & 1185 & $79 \%$ & 470 & $66.9 \%$ \\
\hline \multirow{2}{*}{$\begin{array}{l}\text { Expenses towards medical } \\
\text { care }\end{array}$} & Boys preferred & 183 & $12.2 \%$ & 77 & $11 \%$ \\
\hline & No difference & 1317 & $87.8 \%$ & 626 & $89 \%$ \\
\hline \multirow{2}{*}{$\begin{array}{l}\text { Distribution of household } \\
\text { work }\end{array}$} & Equal & 165 & $11 \%$ & 64 & $9.1 \%$ \\
\hline & Girls more & 1335 & $89 \%$ & 639 & $90.9 \%$ \\
\hline \multirow{2}{*}{ Education Opportunities } & Equal & 212 & $14.1 \%$ & 122 & $17.4 \%$ \\
\hline & Boys more & 1288 & $85.9 \%$ & 581 & $82.6 \%$ \\
\hline \multirow{2}{*}{ Job opportunity } & Equal & 195 & $13 \%$ & 79 & $11.2 \%$ \\
\hline & More for boys & 1305 & $87 \%$ & 624 & $88.8 \%$ \\
\hline \multirow{2}{*}{$\begin{array}{l}\text { Attitude towards daughter's } \\
\text { marriage }\end{array}$} & Not focused & 330 & $22 \%$ & 115 & $16.4 \%$ \\
\hline & Focused & 1170 & $78 \%$ & 588 & $83.6 \%$ \\
\hline \multirow{2}{*}{$\begin{array}{l}\text { Perception of daughter in } \\
\text { the family }\end{array}$} & Burden & 981 & $65.4 \%$ & 553 & $78.7 \%$ \\
\hline & No burden & 519 & $34.6 \%$ & 150 & $21.3 \%$ \\
\hline
\end{tabular}

Table 4 shows that most of the women were not satisfied regarding their status in the family and had some sort of feeling of deprivement as a woman. This was seen more in MP group. More number of women in MP group needed dowry and felt lack of independence while other kind of discriminations as a female were more experienced by MS group women.

When asked about women's attitude towards girl child of their own family, there was no significant difference in both the groups and that was stated almost equal to boys and girls both by majority of women, in regards to diet and health care.

Distribution of household work was allotted more to the girl child, while job opportunities were more planned for boys only, in both the groups most of the women were focussed about daughter's marriage and find them as a burden.

Table 5 shows remarkable difference in regards to distribution of household work to the girl child, while job opportunities were more planned for boys only; in both the groups most of the women were focussed about daughter's marriage and find them as a burden due to additional difficult upbringing of them, but in regards to diet and health care there was no significant difference in both the groups and that was stated almost equal to boys and girls both by majority of women.

Table 6 shows that there are different factors responsible for son preference which were equal for both the groups. Son preference was mostly seen $94.7 \%$ due to various 
cultures and customs out of which dowry is most

commonly told.

Table 6: Different reasons for son preferences in total population.

\begin{tabular}{|llllllll|}
\hline \multirow{2}{*}{ Parameter } & \multicolumn{3}{c}{ Group A } & Group B & \multicolumn{3}{c|}{ Total } \\
\hline \multirow{2}{*}{ Culture and customs } & Yes & 1423 & $94.9 \%$ & 663 & $94.3 \%$ & 2086 & $94.7 \%$ \\
\cline { 2 - 8 } & No & 77 & $5.1 \%$ & 40 & $5.7 \%$ & 117 & $5.3 \%$ \\
\hline \multirow{2}{*}{ Social priority } & Yes & 994 & $66.3 \%$ & 529 & $75.2 \%$ & 1523 & $69.1 \%$ \\
\cline { 2 - 8 } & No & 506 & $33.7 \%$ & 174 & $24.8 \%$ & 680 & $30.9 \%$ \\
\hline \multirow{2}{*}{$\begin{array}{l}\text { Education and job } \\
\text { opportunity }\end{array}$} & Yes & 820 & $54.7 \%$ & 331 & $47.1 \%$ & 1151 & $52.2 \%$ \\
\cline { 2 - 8 } & No & 680 & $45.3 \%$ & 372 & $52.9 \%$ & 1052 & $47.8 \%$ \\
\hline Livelihood generation & Yes & 1110 & $74 \%$ & 553 & $78.7 \%$ & 1663 & $75.5 \%$ \\
\hline $\begin{array}{l}\text { Support to parents at old } \\
\text { age }\end{array}$ & Yes & 1035 & $26 \%$ & 150 & $21.3 \%$ & 540 & $24.5 \%$ \\
\hline \multirow{2}{*}{ All of these } & No & 465 & $31 \%$ & 261 & $62.9 \%$ & 1477 & $67 \%$ \\
\hline
\end{tabular}

Table 7: Opinion about prevention of female foeticide.

\begin{tabular}{|lllll|}
\hline Preventive measures & $\begin{array}{l}\text { Group A } \\
n=1500\end{array}$ & \multicolumn{3}{c|}{$\begin{array}{l}\text { Group B } \\
n=\mathbf{7 0 3}\end{array}$} \\
\hline 1. Continuation of law & 815 & $54.33 \%$ & 573 & $81.50 \%$ \\
\hline 2. Girl education & 945 & $63 \%$ & 490 & $60.70 \%$ \\
\hline 3. Women employment & 1018 & $67.86 \%$ & 501 & $71.26 \%$ \\
\hline 4. No dowry & 1270 & $84.67 \%$ & 690 & $98.15 \%$ \\
\hline 5. Compulsory simplification of marriage & 1215 & $81 \%$ & 655 & $93.17 \%$ \\
\hline $\begin{array}{l}\text { 6. Increased safety and security of girl in } \\
\text { the society }\end{array}$ & 926 & $61.73 \%$ & 478 & $67.99 \%$ \\
\hline $\begin{array}{l}\text { 7. Parents should accept daughter's } \\
\text { support without hesitation }\end{array}$ & 705 & $47 \%$ & 497 & $70.69 \%$ \\
\hline $\begin{array}{l}\text { 8. Withdrawal of age old image of } \\
\text { deprived, discriminated \& damned } \\
\text { womanhood from today's woman. i.e. } \\
\text { by positive campaign of girl as a power }\end{array}$ & 1090 & $72.6 \%$ & 588 & $83.64 \%$ \\
\hline 9. Total social reformation & 1300 & $86.67 \%$ & 679 & $96.58 \%$ \\
\hline 10. Others & 309 & $2 \%$ & 204 & $29.01 \%$ \\
\hline
\end{tabular}

Table 7 shows that most common idea about prevention according to study group was change in the system of marriage especially in regards to dowry $98 \%$ and expenses of ceremony $93 \%$. Total social reformation was recommended by $96 \%$ women to make today's woman more confident, empowered and secured along with continuation of law $81 \%$.

\section{DISCUSSION}

Problem of female foeticide has two basic components: (1) Societal need (2) Service provider. Here we tried to find out factors involved with societal need which indirectly signifies gender inequalities. $\mathrm{Sen}^{5}$ cites seven basic types of gender inequality that comprises the many faces of this problem: mortality inequality; natality inequality; basic facility inequality; special opportunity inequality; professional inequality; ownership inequality; and household inequality.

In our study we found that all these lead to some sort of lack of confidence to the today's women inculcating inability, to welcome another female life as her own girl child in the family, to the extent of willingness to get rid 
off it, many a times unfortunately, they themselves are not even conscious of this hidden deprived image of themselves.

The values of family and lineage are exceedingly strong in India, and self-sacrifice endured to support and maintain them is a prime virtue and duty traditionally accorded to the female.

In our study son preference was significantly less in health workers and other working women than field workers and home makers. That varies from minimum $74.55 \%$ in health workers of MP group to maximum $100 \%$ in field workers of MP. $45 \%$ women in our study were house wives and son preference amongst them was $88-98 \%$, according to study conducted by Basu et al, there is also likely to be a positive association between women's employment and access to knowledge about better childbearing and childrearing practices, as well as a greater confidence and freedom in translating this knowledge into behaviour. This certainly seems to be true in the case of fertility-regulating behaviour and there is no reason to doubt that exposure to and willingness to accept health-related innovations are similarly higher for working women. ${ }^{6}$ Although according to Lancet study ${ }^{7}$ son preference is common in working women and influential families.

In our study, son preference increases with increasing number of children and presence of girl child in the family. In Madhya Pradesh group it was $100 \%$ if even one daughter is present in the family. According to few more studies, sex bias is not generalized, but focused on higher birth order girls. Sex differentials by birth order are far stronger than those by socioeconomic status. ${ }^{8}$

The adjusted sex ratio for the third child was 719 (675762) if the previous two children were girls. By contrast, adjusted sex ratios for second or third births if the previous children were boys were about equal (1102 and 1176 , respectively). ${ }^{7}$

$75.7 \%$ women of MP group and $68 \%$ women of MS group accepted the payment of dowry in their marriages, it was the significant difference $(p$ value $<0.001)$ again proving $\mathrm{MS}$ as a better state. An American study ${ }^{9}$ concluded that adherence to the dowry system, despite being illegal, is a root cause of the problem. Summarily, one way to address the larger problem of sex selection and female neglect is to eliminate the practice of the dowry that reinforces the notion that daughters are lifelong economic liabilities.

Sudha and Rajan argue (1999) that exogamous marriage makes women vulnerable by separating them from their natal families and at the same time placing them amongst marital families who are virtual strangers. In such situations of extreme vulnerability one of the ways to gain acceptance and prove themselves as 'good' daughters-in-law is to give birth to sons. ${ }^{10}$
Some doctors ${ }^{11}$ are completely unabashed about carrying out sex determination tests. According to them it is better to abort a female foetus rather than give birth to her. In all probability, she will be burnt for not bringing enough dowries' (Gupta: 1994). Despite the Anti Dowry Act, the practice continues and is spreading all over the country. The menace of the dowry deaths has increased many fold in Punjab (1744 per cent), and in the neighbouring states of Haryana (78 per cent) and Rajasthan.(162 per cent) in 2002 over 1991 (Crime in India, 1991 and 2002). With such an environment, it is true that those households or parents with more sons are far better off than the parents with more daughters. This costs and benefits trade off leads to killing the girl in the womb than to be burdened with debts or to part with land and house (Grant 1998; Radhakrishnan, 1999). In the near past cases of farmer's suicide have been reported in the national dailies. The cause is not so much crop failure only but the inability to repay debts incurred for a daughter's marriage (Bhalla, 2006) along with. In this way a daughter becomes an avoidable social and economic burden. ${ }^{11}$

Some medical professionals consider themselves as service providers by serving the demand for not facilitating the birth of girl children who are unwanted (Bose, 2002). Further, some of them even feel that they are promoting the cause of family planning by helping families choosing sex composition (Hoskins \& Holmes, 1984; Lingam, 1998) they find themselves serving in favour of women as they become scarce, thereby enhancing their value in the marriage market. ${ }^{12}$

Traditionally women who do work in the fields have comparatively low paid work. In Punjab and Haryana, the situation is exacerbated by the marginalisation of female labour as a result of mechanized agriculture. ${ }^{13}$ Other type of harassments and violence at home and offices are also existing.

Difficult upbringing in respect of safety, biological burden of menstruation and pregnancy was the concern to have a girl child for approximately $17 \%$ of women for their inhibition to have a girl child.

When asking, Is she finds herself independent in terms of day to day activities and especially to support her parents freely both financially and physically? $73.3 \%$ women of MS and $85.6 \%$ women of MP did not find freedom in day to day activities and especially to support their natal parents freely, both financially and physically. Again this difference was significant between two states inspite of being financially independent they are not able to support their natal families and parents financially without asking husband or in laws.

Significantly more number of women, $83 \%$ in MP vs $78 \%$ in MS was focussed towards daughter's marriage only and $65 \%$ in MS vs $78 \%$ in MP finding daughter as a burden. Focussed for marriage/fear of dowry was the main determinant factor behind no to a girl child. 


\section{CONCLUSION}

Marriage related customs, exogamy, death related ceremonies, balancing the family and support at old age are main reasons for negative preferences of female fetuses. In spite of the progress women have made in our country and so many laws to favour them like Sharda Act for child brides and Act against Dowry, different forms of gender discrimination - from dowry to domestic violence to harassment in the workplace - continue practically unabated despite the laws in place leading to feeling of self depreciation in woman of today. Similarly PC \& PNDT Act can only do little without a corresponding change in social mindset. ${ }^{14}$

The negative perception of self image by woman of today does not allow her to welcome another girl child due to fear of repetition of same cycle again, many a times women are not even aware about this self deprived appreciation of herself, which is persisting there in the hidden form.

Service providers are still doing it either because of their different opinion, lower moral values, insensitivity towards ethical aspect of issue or due to little financial greed. This could be dealt with upliftment of moral values of medics by including sensitization programs in their curriculum.

All these measures should be taken by Government simultaneously with a same intensity accepting that decreased sex ratio is a national disaster.

Funding: No funding sources

Competing interests: There are no competing interests to declare

Ethical approval: The study was approved by the institutional ethics committee

\section{REFERENCES}

1. Ramaiah GJ, Chandrasekarayya T, Murthy PV. Declining child sex ratio in India: Trends, Issues and Concerns. Asia Pacific J Social Sci 2011;3:183-98.

2. Mathews TJ, Hamilton BE. National Vital Statistical Reports, NVSS. Number 20 June 14, 2005; 53. Available at http://www.cdc.gov /nchs/data/nvsr/nvsr53/nvsr53_20.pdf.

3. Bardia A, Anand K. Sex ratio in India. Lancet 2006;367:1727-8.
4. Lakshmibai G. India Acid Attacks: Asia calling. 2011 August 13;13:21. Available at www.justclicksearch.com/wiki.php?title=Acid_attac $\mathrm{k}$.

5. Sen A. Many faces of gender inequality. Front line, 2009 Nov 27; 18(22). Available at http://www.flonnet.com/fl1822/18220040.htm.

6. Basu AM, Basu K. Women's economic roles and child survival: the case of India. Delhi, India. Institute of Economic Growth, University Enclave, 1991. Available at htc.anu.edu .au/pdfs /Basu1.pdf.

7. Jha P, Kesler MA, Kumar R, Ram F, Ram U, et al. Trends in selective abortions of girls in India: analysis of nationally representative birth histories from 1990 to 2005 and census data from 1991 to 2011. Lancet 2011;377:1921-8.

8. Das Gupta, M, Maribhat PN. Fertility Decline and Increased Manifestation of Sex Bias in India. Population Investigation Committee. Population Studies 1997;51:307-15.

9. Sineath SA. Son Preference and Sex Selection among Hindus in India. United States, The Florida State University DigiNole Commons. Available at diginole.lib.fsu.edu/cgi/viewcontent. .cgi?article $=4645$

10. Sudha S, Irudaya RS. Female demographic disadvantage in India 1981-1991: sex selective abortions and female infanticide. Dev Change 1999;30:585-618.

11. Mallik R. Negative choice sex determination and sex selective abortion in India, Abortion Assessment Project - India 2003. Available at www.cehat.org.

12. Rustagi P. The Deprived, Discriminated \& Damned Girl Child: Story of Declining Child Sex Ratios in India. New Delhi, Institute for Human Development. 2006. Available at https://tspace. library.utoronto.ca/bitstream/1807/9397/1/Rustagi.pd $\mathrm{f}$.

13. Walia A. Female foeticide in Punjab: Exploring the socio-economic and cultural dimensions. IDEAJ. 2005;10(1) Available at http://www.ideajournal.com/articles.php?id=37.

14. World Health Organization, Department of Reproductive Health and Research. Preventing gender-biased sex Preventing gender-biased sex selection: an interagency statement (2011) OHCHR, UNFPA, UNICEF, UN Women and WHO. Available at www.asiapacificforum.net.

DOI: $10.5455 / 2320-1770 . \mathrm{ijrcog} 20130212$

Cite this article as: Shrivastava D, Patil VS, Shrivastava S, Papalkar J. Determinants of negative preference for female fetuses amongst women of reproductive age group at rural medical college. Int J Reprod Contracept Obstet Gynecol 2013;2:67-73. 